\title{
EXPLORING VIRTUAL REALITY APPLICATION IN TOURISM: VR BUKIT PUTERI
}

\author{
Maizan Mat Amin, Wan Mohd Rizhan Wan Idris, Normala Rahim, \\ Nur Saadah Mohd Sapri, Ismahafezi Ismail, \\ Wan Malini Wan Isa and Muhammad Hazwan Mohamad \\ School of Multimedia, Faculty of Informatics and Computing, \\ Universiti Sultan Zainal Abidin, Besut Campus, \\ 22200, Besut, Terengganu, Malaysia
}

\begin{abstract}
Virtual Reality technologies can play essential role for the success of tourism inventiveness. Hence, this application entitled VR Bukit Puteri is designed and developed as a medium to promote and attract tourists to visit this natural cultural heritage place in Terengganu. This application is particularly very useful for the user to get information or learn interactively about history and artifacts of Bukit Puteri. The interaction design lifecycle model had been implemented in the development of this application. In addition, the gaze interaction technique had been successfully used to add more interactivity and user-friendliness to this application. The framework, interface design, testing and expert evaluation may also serve as guidelines in developing similar VR application in another domain. The author would consider gamification elements, engaging activities, 360'VR experiences to be proposed to enhance VR applications for the future. These engagement elements can be a great counterpart to increase user experience in virtual world.
\end{abstract}

\section{KEYWORDS}

Virtual reality, tourism, expert evaluation, historic place, mobile based VR application

\section{INTRODUCTION}

The Information Communications Technologies (ICT) plays a foremost role in tourism, travel and hospitality industry[1]-[3]. The integration of ICT in the tourism industry is an essential for success of tourism inventiveness. ICTs offer a powerful tool that can bring advantages in accessibility, visibility of information, availability of variety of products and satisfaction and also in promoting and strengthening the tourism industry's strategy and operations.

Virtual Reality (VR) is the use of computer technology to create a simulated environment. VR allows users to experience a sense of presence in a computer-generated, three-dimensional environment. Users are immersed and able to communicate with 3D environments instead of seeing a screen in front of them. The computer is transformed into a gatekeeper for this artificial world by simulating as many senses as possible, such as sight, hearing, touch, and smell. The only limits to near-real VR experiences are the availability of content and cheap computing power.

Tourism is one of popular domain that can apply virtual reality application effectively. Interaction and immersion in a virtual reality are often used for various applications such as promotional content creation, virtual tours, and immersive experiences. VR have been implemented and studied in some virtual hotels or homestays promotions, immersive tourist places, e-museums [4]-[7], virtual tour of theme parks or natural parks, booking services and so on. 
This research focus on the implementation of Mobile based VR application in promoting Bukit Puteri in Terengganu. Bukit Puteri is one of the historical remnants in Malaysia. It has the potential of attracting tourists to visit the place as there are many historical relics there. Bukit Puteri is also a site of natural cultural heritage that is associated with the early history of the beginning of the reign of the Sultanate of Terengganu in the 16th century [8]. The grandeur of Bukit Puteri is still beautiful from its physical. Bukit Puteri was used as a fortress during the reign of the Sultanate of Terengganu from the threat of enemies such as the Siamese and Japanese ones which can be evidenced by the relics of historic artifacts such as Cannons, guerrillas and home of guerrillas, ammunition and weapons stores as weapons of war.

The current approach in promoting Bukit Puteri is only using pamphlets and brochures. Lack of digital documentation has left many people unaware of the existence of the Bukit Puteri. It is ineffective and unattractive method of promotion of Bukit Puteri. With ICT, the promotion can be done globally using websites, social media, panoramic 360 degrees and so on. Besides that, the location of Bukit Puteri on the hill makes it difficult for people with health problems to get on the hill to visit the place. By having this application will help these people to visit this place virtually.

For now, no application yet been developed about Bukit Puteri. Hence, Mobile based VR Bukit Puteri proposed as alternative way in promoting this tourist place. Mobile based VR Bukit Puteri can be used by tourists, students and community to provide a virtual walking tour experience around Bukit Puteri. Three-dimensional models and animations can give user a better experience to explore ins and outs of the Bukit Puteri. This application also developed to foster the spirit of love for historical heritage and also for learning history.

\section{RELATED WORK}

Virtual reality is the use of a fully digital, computer-generated, three-dimensional (3D) experiential environment that the user can navigate and interact with, resulting in real-time simulation of one or more of the user's five senses [7], [9], [10]. The five key elements in experiencing VR are virtual world, immersion, interactivity as well as the people on the content creators and participants [11]. The only limits to a VR experience are the availability of content and computing power. VR allows the user to be immersed in, either non-immersive, semiimmersive, or fully-immersive simulations, and interact with a 3D world that can either simulate or differ completely from the real world.

The immersion in a virtual world is preferably enhanced in natural ways when user can interact with it, Researches had successfully produced a myriad of interaction techniques for VR [12] such as 1) selection, where a set of interaction telling the system which object or user interface element the user wishes to interact with. (examples: Controller input (Laser-pointer or Ray-cast), Gestures, Gaze), 2) manipulation, where a set of interaction actions occurs once an object is selected by the user such as scale, rotate, or translate the selected object and the choice of technique depends on the available input controller's capability. and 3) locomotion, where set of interaction techniques enable user movement such as re-position or re-orient the user within the virtual world (Examples: Locomotion and Vection (Visual illusions of self-motion), On rails, Gaze-directed steering, Teleport and Real movement). The creator of a virtual world has to makes critical decisions on how accessible their world is going to be to the user as VR inputs and interactions are not standardized. The decisions are based on the choice of hardware and the interactions necessary for the VR experience. 
The International Journal of Multimedia \& Its Applications (IJMA) Vol.13, No. 6, December 2021

Tourism is among the domains that might see in Virtual reality (VR) several advances for promoting its products and services. Study by [13] is one of the first that proposes the use of biophysical reactions data for investigating the media effects of a tourism-related VR experience and discusses the use of such technique for studying media effects in VR settings. The specific media characteristics of the VR experience, such as proposing an unusual horizon perspective to the VR viewer, hold the potential to lead to the formation of strong memories might enable a better understanding of the effects of VR technology on consumer behaviour and eventually lead to the design of more engaging VR content.

Research has shown that VR's utmost strength is its capability to visualise spatial environments [7]. Tourism industry from hotels to airlines and travel agencies is looking to capitalise on the VR technology experience to showcase destinations that are visually spectacular, giving customers a multi-sensory engagement experience with the destination even before they book their trip. In addition, VR technology facilitate the loneliness and boredom of the COVID 19 pandemic and allow the potential tourists to "travel" to anywhere in the world without actually being there. This opportunity allows them to explore and be confident with the chosen destinations and help them to make informed decisions. There are few researches of VR in tourism domain [14]-[18]. Challenges in Augmented Reality (AR)/VR studies are lack of VR/AR awareness, usability issues, time commitment required to learn and unwillingness to accept virtual substitutes [14]. In particular, the challenge that consistently appeared were the technical difficulties that affected usability in various categories by potential users. Therefore, there is an essential for research on adaptation and implementation of the optimum VR application as a tourism tool and related domain such travel agency, hotels or homestays, booking services and airlines.

VR technologies and applications can attract a large audience of visitors to see a potential destination and to show how worthy it is to visit. VR also offer an attention-grabbing and immersive VR experience that has exponentially greater impact on increasing visitor intention than traditional media. Besides, it also delivers at relatively small cost. Virtual reality (VR) offers tourism many useful applications that deserve greater attention from tourism researchers and professionals [15]-[20]

The study of VR in Malaysia also is not popular yet. The research of VR of Fascinating Penang [25] discusses the potential of web-based VR to promote tourism sector in Malaysia using panorama model. It provides better user control, requires no high bandwidth demands and can be viewed on standard monitors. This application can be used to attract tourists as it can give initial impression to tourist on what they can expect when visiting Penang. Part of VR's possible utility as a preservation tool derives from its potential to create virtual experiences that tourists may accept as substitutes for real visitation to threatened sites [7] and so on.

\section{Methodology}

\subsection{Human-Centred Design Lifecycle Model}

This Mobile based VR application has been developed using human-centred design lifecycle model or also known as interaction design lifecycle model as shown in Figure 1. It starts with establishing requirement where the researchers collect data and information from Terengganu Museum Department as during this time Bukit Puteri was closed because of under maintenances. Based on gathered information, few alternatives are well-designed using storyboards. From the design, the prototype was developed and evaluated. The process flows are repetitive if needed. 


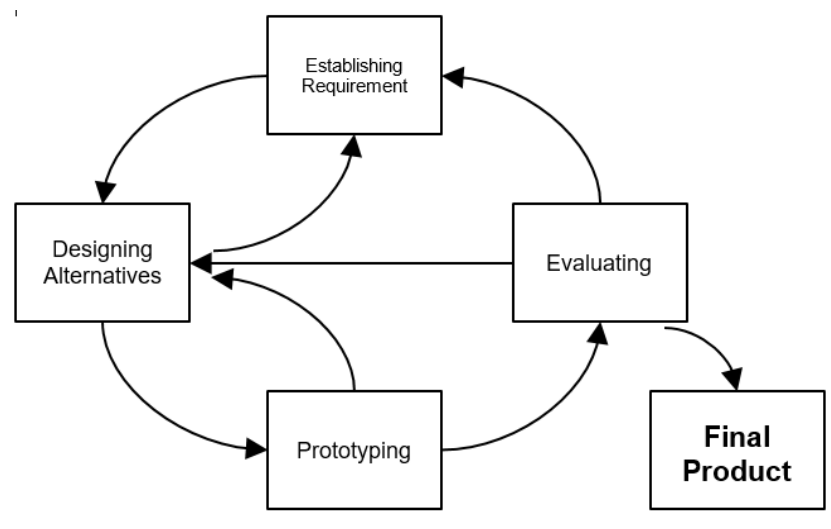

Figure 1. The interaction design lifecycle model

This application had been develop using Maya, Unity 3D, SketchUp, Adobe Illustrator and Adobe Photoshop. The scripting language used in the development of this application is C Sharp (C\#) using Unity 3D software. Unity 3D has a scalable, super-good game engine that fits well for solo developers and small development teams. Similar to other competitors with cool advanced features, the software is considered user-friendly. Unity is the best software for VR application development. It is very effective while rendering 2D scenes. In this era of visual treats, Unity can very well be used for rendering 3D images also. The quality offered is also relatively good compared to other apps.

\subsection{VR Bukit Puteri Framework}

Figure 2 shows the framework of VR Bukit Puteri Application which involves entities such as user, mobile phone as VR platform, Google Cardboard and the VR application. VR platform is where user can test to use VR experience. These SDKs are the building blocks to create VR experiences such as mobile apps, marketing experiences, and more. VR SDKs offer the tools to perform functions such as cloning, moving 3D objects and adding. Google Cardboard is a virtual reality (VR) platform developed by Google for use with a head mount for a smartphone.

A specific method to realize virtual reality includes using a head-mounted display or HMD to bring users to a virtual world that appears to be enclosed in three dimensions. An HMD may include positional tracking, audio and output elements, and haptic feedback. HMDs also can be used to implement virtual reality system specific types. For example, a driving simulator or a projected simulated real-world environment can include the use of an HMD as its main inputoutput equipment. Head-Mounted used in this study because it is affordable and commonly used in VR project.

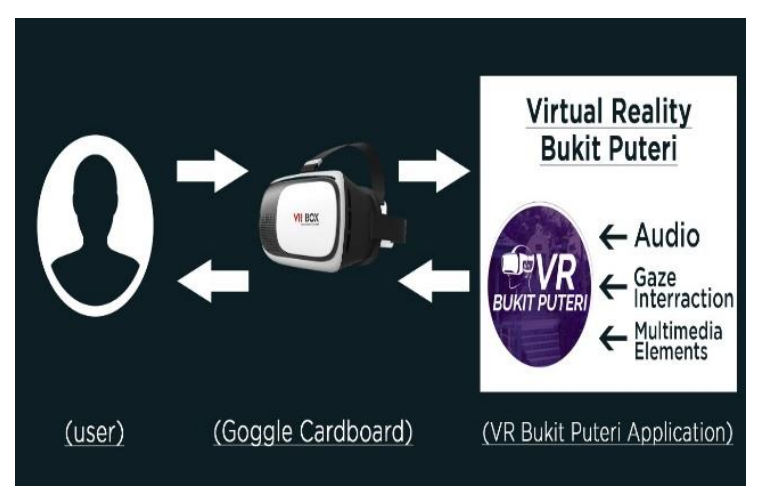

Figure 2. The framework of VR Bukit Puteri application. 
The International Journal of Multimedia \& Its Applications (IJMA) Vol.13, No. 6, December 2021

Virtual Reality hardware produces stimuli that override the senses of the user based on human motions. The VR hardware accomplishes this by using sensors for tracking motions of user such as button presses, controller movements, eye and other body part movements. Google Cardboard is a tool for virtual reality (VR) created by Google to use a smartphone head brace. Named for its fold-out cardboard viewer, the platform is intended as a low-cost device to promote interest and innovation in VR applications. Users can either create their own viewers from basic, low-cost components using Google's published specifications, or buy a pre-produced one. Users run cardboard-compatible apps on their mobile to use the network, place the phone in the viewer's back, and display content through the lenses.

The Cardboard Software Development Kit (SDK) is available for Android and iOS operating systems. The VR View of the SDK allows developers to integrate VR content both on the internet and in their mobile apps. The low cost of Google Cardboard is one of the major reasons why Google Cardboard used in this application. Hence, Google Cardboard is one of the simplest virtual reality headsets to set up and use.

\subsection{Interactive Multimedia Contents}

Virtual reality is an artificial environment that is created with software and presented to the user in such a way that the user suspends belief and accepts it as a real environment. On a computer, virtual reality is primarily experienced through two of the five senses such as sight and sound. This Mobile based VR application used text, graphics, 3D models, audio and other interactive multimedia elements. Each element has been selected to meet the requirements and because its effectiveness of the use. Figure 3 describe the navigation map and contents of the application. The right choice of media selected will enhance user experience in virtual reality application.

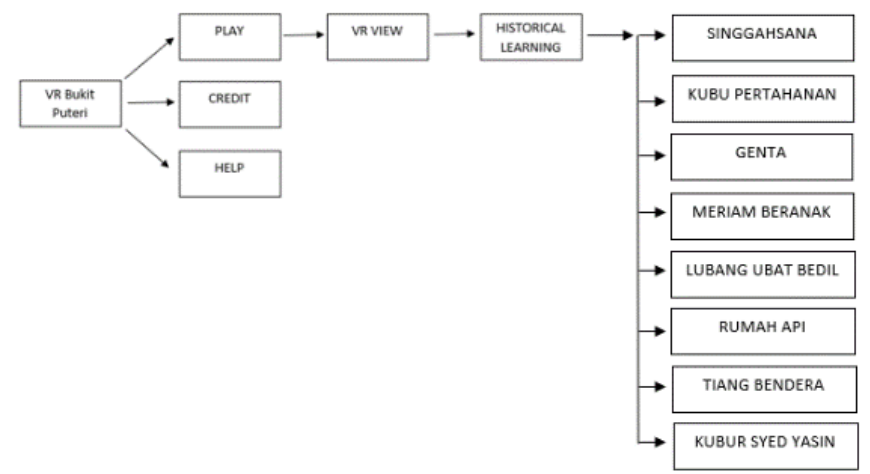

Figure 3. The navigation map and contents of VR Bukit Puteri application.

\subsection{Interaction Styles}

The interaction style used in this study is point of gaze. The point of gaze in the user-computer interaction is recorded and used in real time as an input. In this field researchers are developing more efficient and novel human-computer interfaces to help users with and without disabilities. Person's point of gaze can be used in a variety of ways to control user interfaces, alone or in combination with other types of input such as a mouse, keyboard, sensor, or other devices. A major field of gaze interaction research is discovering more efficient and innovative ways to facilitate interaction between humans and computers for users with disabilities who can only use their eyes for feedback. Certain gaze interaction research focuses on the general use of real-time 
The International Journal of Multimedia \& Its Applications (IJMA) Vol.13, No. 6, December 2021

interactions. Figure 4 is the example of the point of gaze method. This technique can allow user to interact with the object in this application to see the information.

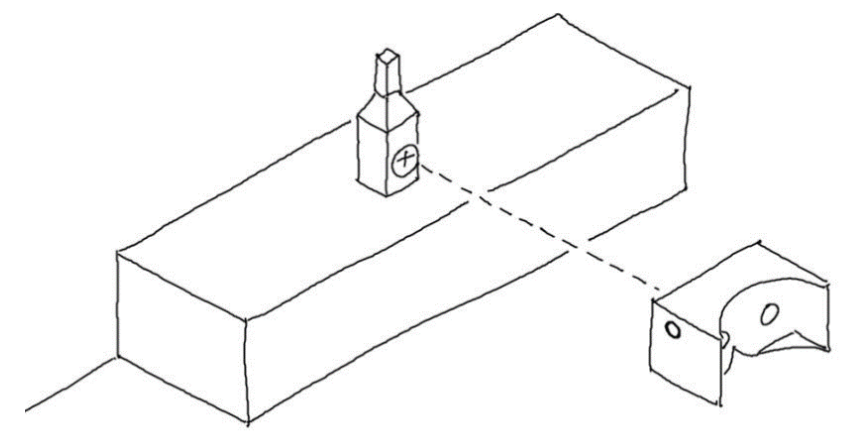

Figure 4. Example of the point of gaze method

\subsection{Expert Evaluation}

Heuristic evaluation had been conducted focused on the VR Bukit Puteri interface design by setting an experiment with at least three experts [26][27]. Ten (10) heuristics criteria are considered in measuring the interfaces. The three phases involved are: Set the objective, Testing and Data Collection. The testing session were conducted by setting an experiment through offline activities in the Multimedia laboratory involved three experts.

The heuristic evaluation was carried-out using questionnaires instrument in collecting the data. Experts evaluate and give feedbacks based on the user interface of VR Bukit Puteri, and then the data had been analysed.

\section{RESULTS AND DISCUSSION}

The VR application is implemented into a real prototype and integrated with application-based service for the end-user. The application testing is executed to test the whole application for the functionality and credibility of the application been developed. This section discusses the implementation, deployment and the results of the entire application. The analysis results from heuristic evaluation by experts also presents in the section.

\subsection{Deployment and Configuration}

In the deployment stage, the hardware requirement is setup and tested either it is suitable and compatible with the application requirement. To use the platform, users need to run VR Cardboard-compatible applications on their phone, place the phone into the back of the viewer, and view content through the lenses. To play this application, user should use google cardboard to connect to the application Then, the application will provide a virtual reality view in Google Cardboard and the user will feel immersed in the environment. The task is completed by allowing the display at the Google Cardboard with the right setting. 
The International Journal of Multimedia \& Its Applications (IJMA) Vol.13, No. 6, December 2021

\subsection{Interfaces}

Implementation of the application is the process of identifying how to construct the information application like the physical application design and ensuring that the information in the application is operational and used. Furthermore, the generated interface design should be based on user requirements.

Figure 5 show the Main Menu page for Mobile based VR Bukit Puteri. In main menu, users have options either to start explore Bukit Puteri Environment or to view the credit. If user gaze on Play button, the journey to Bukit Puteri is begin.

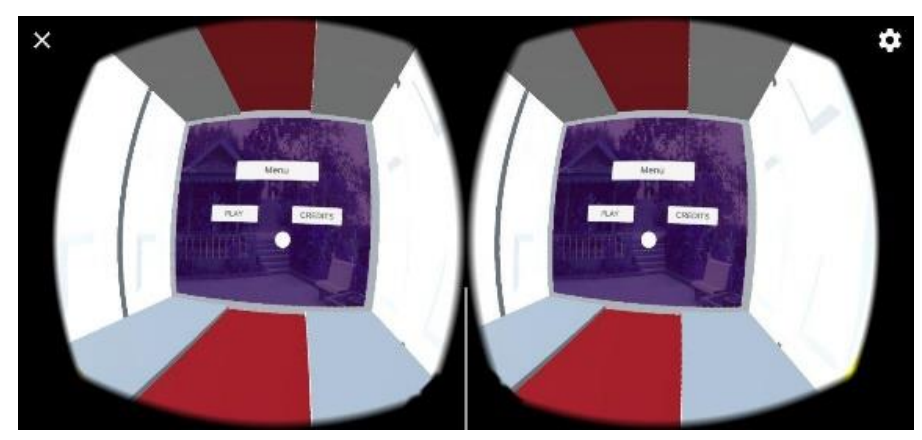

Figure 5. The main menu page

As shown in Figure 6 and 7, If the user chose to play the application, user can have information about Bukit Puteri and can view the Gallery of VR Bukit Puteri. User can see the actual environment of Bukit Puteri in the scene.

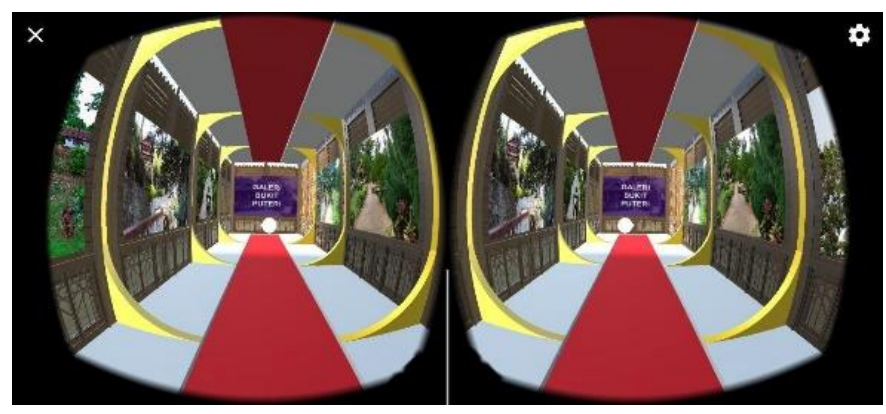

Figure 6. The Gallery of VR Bukit Puteri view

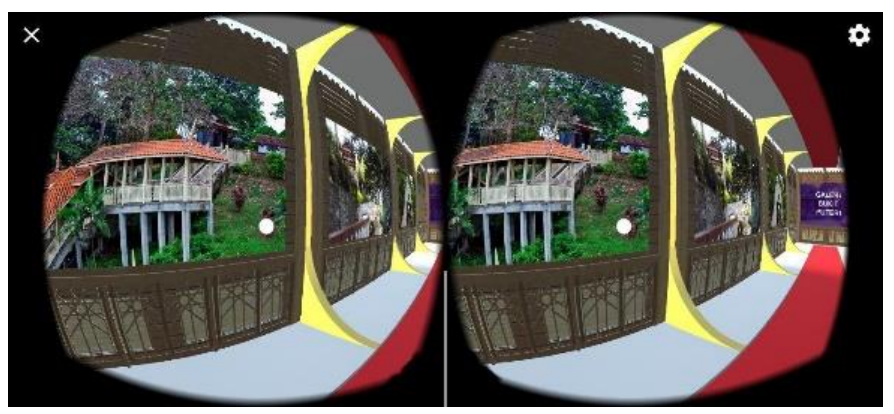

Figure 7. The Gallery of VR Bukit Puteri view. 
The International Journal of Multimedia \& Its Applications (IJMA) Vol.13, No. 6, December 2021

This Mobile based VR application featuring eight (8) historical artifacts and information of existing monuments and artifacts in Bukit Puteri. which are Singgahsana, Kubu Pertahanan, Genta (Loceng Besar), Meriam Beranak, Lubang Ubat Bedil, Rumah Api, Tiang Bendera and Kubur Syed Yasin. Figure 8 and 9 shows among few views of monuments in VR Bukit Puteri which are Kubu Pertahanan and Lubang Ubat Bedil.

For each monuments or artifacts, when user gaze on each virtual board, it displays the interactive information about name, function and age of the artifacts or monument. The user only needs to gaze the name of the artefact and the historical narration and information appear. When user stand in front of the artifacts virtual board, the audio of the artifact's information will automatically play.

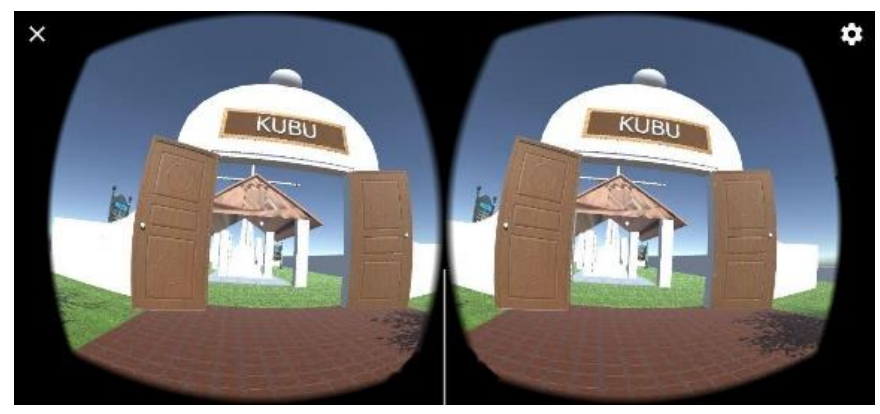

Figure 8. The view of Kubu Pertahanan

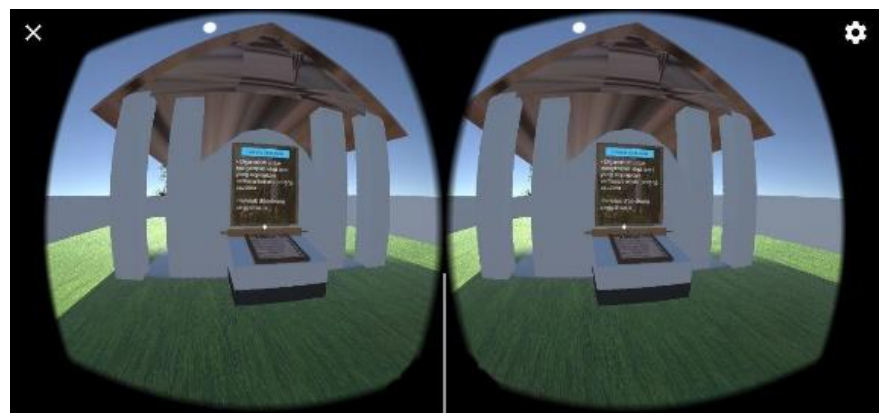

Figure 9. The view of Lubang Ubat Bedil

The application also provided with interesting sound effect and background music to enhance user experience. The monuments and artifacts have been modelled in three-dimensional (3D) modelling which have almost same texture and layout with actual one for user be able feel like they are actually present at there.

User be able to explore VR Bukit Puteri with supported by Google Cardboard. By using 3D models and virtual environment, users can easily familiarize the monument and historical remnants very well. The user also able to obtain information about the existing monument and know some historical artifacts in Bukit Puteri. Besides, by using mobile application, it can provide best way to interact with the virtual tour and emerging with the environment.

\subsection{Testing}

Testing is a process which the execution is performed with the intent to identify the errors, ensures that the application is functional and meets its quality standard. A few tests for the application had been performed during and after the development process. Testing is important to 
The International Journal of Multimedia \& Its Applications (IJMA) Vol.13, No. 6, December 2021

check the full operation of the system and to free errors. This application has been tested in three forms which are unit testing, integrate testing and application testing.

Unit testing is performed to verify the functionality of specific section code and integration testing works for exposed interface defects and interaction among modules. End-to-end testing or application testing is performed on a complete integrated application to check that it meets its needs.

A test case is a collection of conditions or variables in which a tester must determine whether a requirement is partially or entirely fulfilled upon application. A test case can also be described as a sequence of steps to check the proper functionality or application feature behaviour. In a test case, there is a list of steps, tests, procedures and expected results will be stated in a test case. Table 1 to 6 shows the successfully test cases that had been done.

Table 1. Test case for successful of open the application

\begin{tabular}{|c|c|c|c|}
\hline \multicolumn{4}{|c|}{ Test case for successful of open the application } \\
\hline Steps & Test Procedure & Expected Output & Result \\
\hline 1. & Open the application & $\begin{array}{c}\text { The home page and Enter button will } \\
\text { appear }\end{array}$ & Success \\
\hline
\end{tabular}

Table 2. Test case for successful of open the Home page

\begin{tabular}{|c|c|c|c|}
\hline \multicolumn{4}{|c|}{ Test case for successful of the home page. } \\
\hline Steps & Test Procedure & Expected Output & Result \\
\hline 1. & Gaze Enter button & The main menu scene will appear & Success \\
\hline
\end{tabular}

Table 3. Test case for successful of Main Menu Page

\begin{tabular}{|c|c|c|c|}
\hline \multicolumn{4}{|c|}{ Test case for successful of the main menu page. } \\
\hline Steps & Test Procedure & Expected Output & Result \\
\hline 1. & Gaze Play button & $\begin{array}{c}\text { User can navigate to Bukit Puteri } \\
\text { virtual reality en vironment }\end{array}$ & Success \\
\hline 2. & Gaze Credit button & $\begin{array}{c}\text { View the Credits of VR Bukit } \\
\text { Puteri development }\end{array}$ & Success \\
\hline
\end{tabular}

Table 4. Test case for successful gaze interaction of information

\begin{tabular}{|c|c|c|c|}
\hline \multicolumn{5}{|c|}{ Test case for successful of audio interaction in VR environment. } \\
\hline $\begin{array}{c}\text { Step } \\
\text { S }\end{array}$ & Test Procedure & Expected Output & Result \\
\hline 1. & User gaze to the Kubu artifact & Information about Kubu & Success \\
\hline 2. & User gaze to the Singgahsana artifact & Information about Singgahsana & Success \\
& & & \\
\hline
\end{tabular}


The International Journal of Multimedia \& Its Applications (IJMA) Vol.13, No. 6, December 2021

\begin{tabular}{|c|c|c|c|}
\hline 3. & $\begin{array}{c}\text { User gaze to the Lubang Ubat Bedil } \\
\text { artifact }\end{array}$ & $\begin{array}{c}\text { Information about Lubang Ubat } \\
\text { Bedil }\end{array}$ & Success \\
\hline 4. & User gaze to the Tiang bendera artifact & Information about Tiang bendera & Success \\
\hline 5. & User gaze to the Rumah Api artifact & Information about Rumah Api & Success \\
\hline 6. & User gaze to the Rumah Genta artifact & Information about Rumah Genta & Success \\
\hline 7. & $\begin{array}{c}\text { User gaze to the Meriam Beranak artifact } \\
\text { Information about Meriam Beranak }\end{array}$ & Success \\
\hline 8. & User gaze to the Kubur Syed Yasin \\
artifact & Information about Kubur Syed Yasin & Success \\
\hline
\end{tabular}

Table 5. Test case for successful audio interaction

\begin{tabular}{|c|c|c|c|}
\hline \multicolumn{4}{|c|}{ Test case for successful of audio interaction in VR environment. } \\
\hline Steps & $\begin{array}{c}\text { Test Procedure } \\
\end{array}$ & Expected Output & Result \\
\hline 1. & $\begin{array}{l}\text { User approaches distance with } K u b u \\
\text { virtual board }\end{array}$ & Audio tells about $K u b u$ & Success \\
\hline 2. & $\begin{array}{l}\text { User approaches distance with } \\
\text { Singgahsana virtual board }\end{array}$ & Audio tells about Singgahsana & Success \\
\hline 3. & $\begin{array}{c}\text { User approaches distance with Lubang } \\
\text { Ubat Bedil virtual board }\end{array}$ & Audio tells about Lubang Ubat Bedil & Success \\
\hline 4. & $\begin{array}{l}\text { User approaches distance with Tiang } \\
\text { bendera virtual board }\end{array}$ & Audio tells about Tiang bendera & Success \\
\hline 5. & $\begin{array}{l}\text { User approaches distance with Rumah } \\
\text { Api virtual board }\end{array}$ & Audio tells about Rumah Api & Success \\
\hline 6. & $\begin{array}{l}\text { User approaches distance with Rumah } \\
\text { Genta } \text { virtual board }\end{array}$ & Audio tells about Rumah Genta & Success \\
\hline 7. & $\begin{array}{c}\text { User approaches distance with Meriam } \\
\text { Beranak virtual board }\end{array}$ & Audio tells about Meriam Beranak & Success \\
\hline 8. & $\begin{array}{l}\text { User approaches distance with Kubur } \\
\text { Syed Yasin virtual board }\end{array}$ & Audio tells about Kubur Syed Yasin & Success \\
\hline
\end{tabular}

Table 6. Test case for successful of exit the application

\begin{tabular}{|c|c|c|c|}
\hline \multicolumn{4}{|c|}{ Test case for successful of exit page } \\
\hline Steps & Test Procedure & Expected Output & Result \\
\hline 1. & $\begin{array}{c}\text { Click the exit button on the virtual } \\
\text { reality view }\end{array}$ & Redirect exit the application & Success \\
\hline
\end{tabular}


The International Journal of Multimedia \& Its Applications (IJMA) Vol.13, No. 6, December 2021

\subsection{Heuristic Evaluation}

Table VII summarized on heuristic evaluation for VR Bukit Puteri application. It presents the mean score of the result from heuristic evaluation analysis. The result shown that most of the criteria of heuristic evaluation scored an average of 4.00 and above except the Heuristic 10 (H10Help and documentation), which achieved 3.70 of average score. The Heuristic 1 (H1-Visibility of system status) and Heuristic 2 (H2- Match between application and the real world) gained the highest score with 4.7 average score. Although this application already has its help and documentation, however based on the experts' feedback, some modifications need to be done to further improve and therefore increase the usability.

Few related feedbacks and comments also were gathered from the experts. The comments are as follows:

1) This application encloses a new approach to engage people using mobile or computer application by utilizing virtual reality technology in tourism and historical places learning.

2) The usage of multimedia elements (3D models, audio, graphic), is very attractive to users.

3) The interactions between user and historical artifacts motivate users to quest for the information and keep learning

Table 7. Results from Expert Evaluation

\begin{tabular}{|c|c|c|}
\hline Heuristics & Characteristics of VR Bukit Puteri application & $\begin{array}{l}\text { Mean } \\
\text { Score }\end{array}$ \\
\hline $\begin{array}{l}\text { Visibility of } \\
\text { application status }\end{array}$ & $\begin{array}{l}\text { The VR Bukit Puteri always keep users informed about what } \\
\text { is going on, through appropriate feedback within reasonable } \\
\text { time. }\end{array}$ & 4.70 \\
\hline $\begin{array}{l}\text { Match between } \\
\text { application and the } \\
\text { real world }\end{array}$ & $\begin{array}{l}\text { The concept of VR Bukit Puteri used common and easy } \\
\text { terminology, nature environment as identical to Bukit Puteri } \\
\text { environment such as historical artifacts and surroundings. } \\
\text { The application encourages the user to interact with } \\
\text { historical artifacts objects to seek for information. Besides it } \\
\text { also provides real views in Bukit Puteri Gallery menu. }\end{array}$ & 4.70 \\
\hline $\begin{array}{l}\text { User control and } \\
\text { freedom }\end{array}$ & $\begin{array}{l}\text { The VR Bukit Puteri provides fredom to user to move } \\
\text { around and can interact with application by gazing the } \\
\text { objects for more information. }\end{array}$ & 4.30 \\
\hline $\begin{array}{l}\text { Consistency and } \\
\text { standards }\end{array}$ & $\begin{array}{l}\text { The user needs to gaze at an interaction buttons or menus } \\
\text { within Bukit Puteri consistently. }\end{array}$ & 4.30 \\
\hline Error prevention & $\begin{array}{l}\text { VR Bukit Puteri present users with a confirmation option } \\
\text { before they commit to the action. }\end{array}$ & 4.00 \\
\hline $\begin{array}{l}\text { Recognition rather } \\
\text { than recall }\end{array}$ & $\begin{array}{l}\text { In VR Bukit Puteri, the interaction buttons or menus always } \\
\text { visible to the user on the screen. So, they easily navigate and } \\
\text { control the application. }\end{array}$ & 4.30 \\
\hline $\begin{array}{l}\text { Flexibility and } \\
\text { efficiency of use }\end{array}$ & $\begin{array}{l}\text { While exploring the VR Bukit Puteri, the application can } \\
\text { cater to both inexperienced and experienced users. It also } \\
\text { allows users to tailor frequent actions. }\end{array}$ & 4.00 \\
\hline $\begin{array}{l}\text { Aesthetic and } \\
\text { minimalist design }\end{array}$ & $\begin{array}{l}\text { Interaction in VR Bukit Puteri designed relevant with related } \\
\text { information. }\end{array}$ & 4.00 \\
\hline $\begin{array}{l}\text { Help users } \\
\text { recognize, diagnose, } \\
\text { and recover from } \\
\text { errors }\end{array}$ & $\begin{array}{l}\text { VR Bukit Puteri used simple and plain language to help user } \\
\text { during exploring the application. If user gaze at certain } \\
\text { button or menu, user will be notify using dialogue box. }\end{array}$ & 4.00 \\
\hline $\begin{array}{l}\text { Help and } \\
\text { documentation }\end{array}$ & $\begin{array}{l}\text { VR Bukit Puteri provide help button at main menu for } \\
\text { reference in exploring the application. }\end{array}$ & 3.70 \\
\hline
\end{tabular}


The International Journal of Multimedia \& Its Applications (IJMA) Vol.13, No. 6, December 2021

Results from the usability testing and feedbacks from the expert's evaluation can be a good guidance for developing next implementation of VR applications. The application can be studied for other platforms, environments, types of interactions, as well as other persistence. The author would consider gamification elements and engaging activities to be proposed to enhance VR applications for the future. These engagement elements can be a great counterpart to increase user experience in virtual world. Some consideration for future studies is to explore on 360' VR experiences. The emergence of $360^{\prime}$ cameras alongside the various head-mounted displays facilitates to create VR experiences without the need to have technical skills and exponentially will increase VR contents ready to be consumed. In addition, Social media platforms such as Instagram, YouTube and Facebook also will contribute to this purpose as it readily supports VR. These adaptations of VR technology could potentially grow the tourism industry and other domain rapidly.

\section{CONCluSion}

In conclusion, the aim of study in developing Mobile based VR Bukit Puteri application has been accomplished with success. This application is particularly very useful for the user to get information or learn interactively about history and artifacts of Bukit Puteri. The interaction design lifecycle model had been implemented in the development of this application. The framework and interface design may also serve as guidelines in developing similar application in another domain. In addition, the gaze interaction technique had been successfully used to add more interactivity and user-friendliness to this application. The expert evaluation shows the application meet the usability evaluation and can be improve more in few aspects. In future works, this VR application may be improved and utilized for other platforms, environments and types of interactions as well. Besides it should consider to offer multilingual for the information provided to make it useful for more users globally. Lastly, this VR application can also be developed with $360^{\prime}$ 'VR experiences, more interactivity such as adding some gamification elements, game or quiz, so that users can 'tour' while learn or/and play with it.

\section{ACKNOWLEDGEMENTS}

The authors would like to thank Center for Research Excellence and Incubation Management (CREIM), Universiti Sultan Zainal Abidin.

\section{REFERENCES}

[1] W. M. R. W. (2017) Amin, M. M., Rahim, N., Safei, S., \& Idris, "Utilization of Automated Virtual Panoramic Environment in Online Public Accommodation Booking System,” J. Telecommun. Electron. Comput. Eng., no. 9(2-4), pp. 59-63, 2017.

[2] R. Rahim, N., Wook, T. S. M. T., MatZin, N. A., Rawi, N. A., \& Muda, "Usability Evaluation of a Virtual Museum Environment: A Case Study in Terengganu State Museum, Malaysia,” Adv. Sci. Lett., vol. 22(10), pp. 2780-2784, 2016.

[3] A. R. Amin, M. M., Lan, J. Y. A., Makhtar, M., \& Mamat, "A Decision Tree Based Recommender System for Backpackers Accommodations,” Int. J. Eng. Technol., vol. 7(2.15), pp. 45-48, 2018.

[4] A. Bec, B. Moyle, K. Timms, V. Schaffer, L. Skavronskaya, and C. Little, "Management of immersive heritage tourism experiencs: A conceptual model," Tour. Manag., 2019, doi: 10.1016/j.tourman.2018.10.033.

[5] J. P. Guerra, M. M. Pinto, and C. Beato, "Virtual Reality - Shows a New Vision for Tourism and Heritage," Eur. Sci. J., 2015.

[6] F. Poux, Q. Valembois, C. Mattes, L. Kobbelt, and R. Billen, "Initial user-centered design of a virtual reality heritage system: Applications for digital tourism," Remote Sens., vol. 12, no. 16, 2020, doi: 10.3390/RS12162583. 
The International Journal of Multimedia \& Its Applications (IJMA) Vol.13, No. 6, December 2021

[7] D. A. Guttentag, "Virtual reality: Applications and implications for tourism," Tour. Manag., 2010, doi: 10.1016/j.tourman.2009.07.003.

[8] M. Harun, M. N. S., \& Samsudin, "Sejarah Bukit Puteri Sebagai Tapak Warisan Kebudayaan Semulajadi di Negeri Terengganu,” J. Perad., vol. 12(1), pp. 103-118, 2019.

[9] P. Burdea, G. C., \& Coiffet, Virtual reality technology (Vol. 1). John Wiley \& Sons., 2003.

[10] D. Gutierrez, M., Vexo, F., \& Thalmann, Stepping into virtual reality. London: Springer Science \& Business Media., 2008.

[11] A. B. (2018) Sherman, W. R., \& Craig, Understanding Virtual Reality: Interface, Application, and Design (The Morgan Kaufmann Series in Computer Graphics) 2nd Edition. Morgan Kaufmann Publication, 2018.

[12] M. R. Mine, "Virtual Environment Interaction Techniques," Virtual Environ. Interact. Tech., vol. UNC Chapel, 1995.

[13] E. Marchiori, E. Niforatos, and L. Preto, "Measuring the Media Effects of a Tourism-Related Virtual Reality Experience Using Biophysical Data," in Information and Communication Technologies in Tourism 2017, 2017.

[14] R. Yung and C. Khoo-Lattimore, "New realities: a systematic literature review on virtual reality and augmented reality in tourism research," Curr. Issues Tour., vol. 22, no. 17, pp. 2056-2081, 2019, doi: 10.1080/13683500.2017.1417359.

[15] N. E. M. Mofokeng and T. K. Matima, "Future tourism trends: Virtual Reality based tourism utilizing Distributed Ledger Technologies,” African J. Hosp. Tour. Leis., vol. 7, no. 3, pp. 1-14, 2018.

[16] J. Beck, M. Rainoldi, and R. Egger, "Virtual reality in tourism: a state-of-the-art review," Tour. Rev., vol. 74, no. 3, pp. 586-612, 2019, doi: 10.1108/TR-03-2017-0049.

[17] A. Racz and G. Zilizi, "Virtual Reality Aided Tourism," 2019 Smart Cities Symp. Prague, SCSP 2019 - Proc., no. August, 2019, doi: 10.1109/SCSP.2019.8805727.

[18] M. J. Kim and C. M. Hall, "A hedonic motivation model in virtual reality tourism: Comparing visitors and non-visitors," Int. J. Inf. Manage., vol. 46, pp. 236-249, 2019, doi: 10.1016/j.ijinfomgt.2018.11.016.

[19] T. Jung, M. C. T. Dieck, N. Moorhouse, and D. T. Dieck, "Tourists' experience of Virtual Reality applications," in 2017 IEEE International Conference on Consumer Electronics, ICCE 2017, 2017, doi: 10.1109/ICCE.2017.7889287.

[20] Y. C. Huang, K. F. Backman, S. J. Backman, and L. L. Chang, "Exploring the Implications of Virtual Reality Technology in Tourism Marketing: An Integrated Research Framework,” Int. J. Tour. Res., 2016, doi: 10.1002/jtr.2038.

[21] R. Yung and C. Khoo-Lattimore, "New realities: a systematic literature review on virtual reality and augmented reality in tourism research," Curr. Issues Tour., vol. 22, no. 17, pp. 2056-2081, Oct. 2019, doi: 10.1080/13683500.2017.1417359.

[22] S. M. C. Loureiro, J. Guerreiro, and F. Ali, "20 years of research on virtual reality and augmented reality in tourism context: A text-mining approach," Tourism Management. 2020, doi: 10.1016/j.tourman.2019.104028.

[23] A. Nayyar, B. Mahapatra, D. N. Le, and G. Suseendran, "Virtual Reality (VR) \& Augmented Reality (AR) technologies for tourism and hospitality industry," Int. J. Eng. Technol., 2018, doi: 10.14419/ijet.v7i2.21.11858.

[24] N. Rahim, N. Abd Hamid, W. M. Wan Isa, S. D. Mohd Satar, and A. Rozaimee, “A Survey on Components of Virtual 'Umrah Application,” Int. J. Multimed. Its Appl., vol. 5, no. 5, pp. 17-27, 2013, doi: 10.5121/ijma.2013.5502.

[25] H. Syahida, "Virtual Reality Application in Tourism Sector: Fascinating Penang," Universiti Utara Malaysia, 2003.

[26] R. Nielsen J. and Molich, "Heuristic evaluation of user interfaces," in Proceedings of the SIGCHI Conference on Human Factors in Computing Systems, 1990, pp. 249-256.

[27] N. Amin, M. M., Rawi, N. A., Isa, W. M. W., \& Rahim, "Heuristic evaluation of usability for gamified co-curricular lesson: A study case of learn to scout.," Adv. Sci. Lett., vol. 23(5), pp. 41974201., 2017. 
The International Journal of Multimedia \& Its Applications (IJMA) Vol.13, No. 6, December 2021

\section{AuTHORS}

Maizan Mat Amin obtained her Master of Science (Computer Science) majoring Multimedia in 2003 from Universiti Putra Malaysia, Bachelor of Information Technology (Information Science) in 1999 from Universiti Kebangsaan Malaysia (UKM), and Diploma of Information Technology from Kolej Agama Sultan Zainal Abidin (currently known as Universiti Sultan Zainal Abidin (UniSZA)). She joined Universiti Sultan Zainal Abidin (UniSZA), Terengganu, Malaysia since 1999 and one of the Senior Lecturer at School of Multimedia, Faculty of Informatics and Computing,

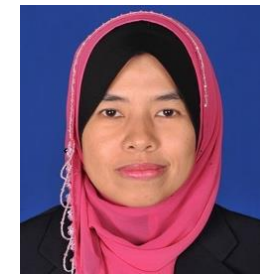
UniSZA. She has published more than 30 articles with H-index four (Google Scholar). Her research interests are in Multimedia, Human Computer Interaction, Visual Informatics, Virtual and Augmented Reality, Gamification and e-Learning.

Wan Mohd Rizhan Wan Idris, is currently a senior lecturer in Faculty of Informatics \& Computing, Sultan Zainal Abidin University (UniSZA) in Besut Campus under School of Multimedia Study. He received his Master of Science (Multimedia) and Ph.D in Creative Multimedia since 2010 and 2020. His main research areas focus on motion capture, motion recognition, virtual reality and 3D animation.

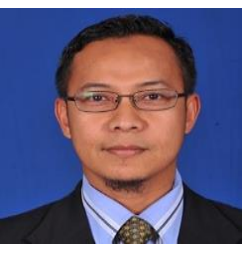

Normala Rahim received the Diploma and Bachelor's degree in Photography and Creative Imaging from the Universiti Teknologi MARA (UiTM) in 2006 and 2008, respectively. She was awarded the Master's and Ph.D. degree in Information Technology from the Universiti Kebangsaan Malaysia in 2012 and 2020, respectively. She is currently a Senior Lecturer and the Program Coordinator for Diploma of Information Technology (Multimedia), Faculty of Informatics \& Computing, Universiti

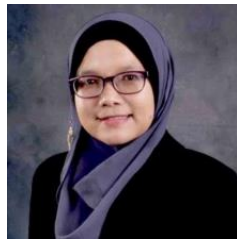
Sultan Zainal Abidin. Her research interests include Human-Computer interaction that includes the multimedia application, user interaction design, usability \& user experience, virtual and augmented reality, and e-learning.

Nur Saadah Mohd Shapri is a Senior Lecturer in Faculty Informatic and Computing in Universiti Sultan Zainal Abidin (UniSZA). She holds a $\mathrm{PhD}$ in Computer Science (Industrial Computing) from National University of Malaysia (Universiti Kebangsaan Malaysia, UKM). Her research area is in Computer Graphics and Simulation, Multimedia Computer Programming Games Design \& Development Visualization, Simulation Computer Graphics Application \& Techniques, Collision Detection between 3D and Deformable Models in Virtual Environment. She is a reviewer of more than 10 international journals and conference proceedings. He is also a member of the International Association of Engineers in Computer Science Society (IAENG) and ORACLE.

Ismahafezi Ismail is a Senior Lecturer at the Faculty of Informatics and Computing, Universiti Sultan Zainal Abidin (UniSZA), Malaysia. His research focuses on computer games, computer animation, virtual reality, and augmented reality.

Wan Malini Wan Isa received the B.Sc. degree (Hons.) in computer science from Universiti Putra Malaysia (UPM), Malaysia, in 2006, and the M.Sc. degree in computer science from Universiti Putra Malaysia (UPM), Malaysia in 2008. In 2009, she joined Universiti Sultan Zainal Abidin (UniSZA), Malaysia, as a Lecturer. She was awarded Ph.D. degree in Information Technology from the Universiti Kebangsaan Malaysia in 2021. She has published more than 20 articles with a citation of 100 and H-index six (Google Scholar). Her research interests include multimedia application, knowledge base, serious games, human computer interaction and e-learning.

Muhammad Hazwan Mohamad received the Diploma in information Technology on 2017 and Bachelor of Information Technology (Informatics Media) on 2021 from University Sultan Zainal Abidin (UniSZA).
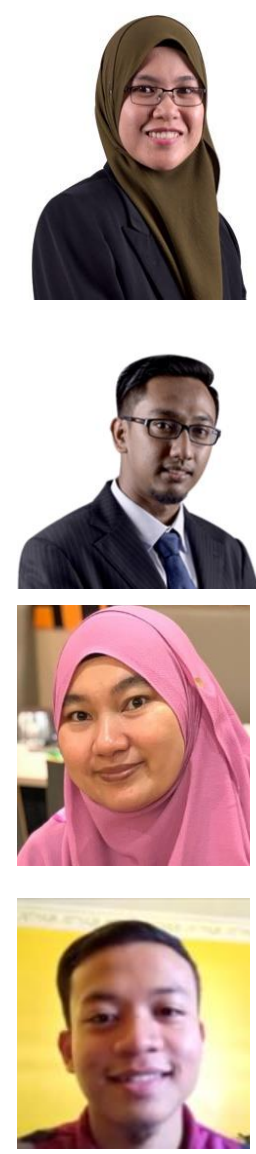